ing from Murcia, Spain. She was born in 1987, without meconium ileus, and was diagnosed as having cystic fibrosis at the age of 5 months, on the basis of growth retardation gastrointestinal problems (especially diarrhoea and steatorrhoea), and repeated bronchitis. Staphylococcus aureus then Pseudomonas aeruginosa have been found in the patient's sputum since she was 6 months old. She is treated with pancreatic enzymes and antibiotics, but her obstructive lung disease has increased and the patient is classified as severely affected by the clinicians.

Using the SSCP technique ${ }^{11}$ to study the DNA extracted from the patient and her family, we detected then identified the stop mutation G542X in the two CFTR genes transmitted to the affected child. This mutation is associated with haplotype 1121221 on the paternal chromosome, and with haplotype 1221221 on the maternal chromosome, as defined by the markers met $\mathrm{D} / \mathrm{Taq} \mathrm{I}$, met $\mathrm{H} /$ TaqI, G2/XbaI, XV2C/TaqI, KM19/ Pst I, D9/MspI, and J3.11/MspI.

The stop mutation $\mathrm{G} 542 \mathrm{X}$ is predicted to result in decreased levels of mutant messenger RNA $^{12}$ and in a truncated CFTR protein from NBD-1, ${ }^{1}$ suppressing $63 \%$ of the molecule. However, the homozygous patients for G542X previously reported had mild pulmonary disease, ${ }^{3-510}$ which would imply alternative splicing mechanisms suppressing the effect of the stop mutation in some tissues. Contrasting with these reports, we present the second case of a child homozygous for G542X with severe pancreatic and lung disease. Another similar finding has just been reported in a Turkish boy in the neonatal period by Bienvenu et al. ${ }^{13}$ Such contradictions in genotype/phenotype correlations might be resolved in the future by mRNA and protein expression studies in target tissues.

We wish to express our gratitude to the Association Française de Lutte contre la Mucoviscidose quet.

MARIE DESGEORGES MAGUELONE LAUSSEL BERNARD ROLLIN JACQUES DEMAILLE MIREILLE CLAUSTRES Laboratoire de Biochimie Génétique, CRBM U249 and GREPAM, Institut de Biologie, Bd Henri IV

34060 Montpellier, France.

1 Kerem B, Zielenski J, Markiewicz D, et al. Identification of mutations in regions corresponding to the 2 putative nucleotide (ATP)binding folds of the cystic fibrosis gene. Proc Natl Acad Sci USA 1990;87:8447-51.

2 Claustres $M$, Laussel $M$, Desgeorges $M$, et al. Analysis of the 27 exons and flanking regions of the cystic fibrosis gene: $\mathbf{4 0}$ different mutations account for $92.1 \%$ of the mutant alleles in Southern France. Hum Mol Genet 1993;2:1209-13.

3 Bonduelle M, Lissens W, Liebaers I, et al. Mild cystic fibrosis for G542 non-sense mutation in CF gene. Lancet 1991;338:189.

4 Beaudet AL, Perciaccante RG, Cutting GR. Homozygous nonsense mutation causing cystic fibrosis with uniparental disomy. $A m \mathcal{F}$ Hum Genet 1991;48:1213.

5 Cuppens H, Marynen P, De Boeck C, et al. A child, homozygous for a stop codon in exon 11 , shows milder cystic fibrosis symptoms than her heterozygous nephew. $\mathcal{f}$ Med Genet 1990;27:717-19.

6 Gasparini P, Borgo G, Mastella G, et al. Nine cystic fibrosis patients homozygous for the CFTR nonsense mutation R1162X have mild or moderate lung disease. $\mathcal{f}$ Med Genet 1992;29:558-62.

7 Bal J, Stuhrmann M, Schloesser M, et al. A cystic fibrosis patient homozygous for the nonsense mutation R553X 7 Med Genet 1991;28:715-17.
8 Cheadle J, Al-Jader L, Goodchild M, Meredith AL. Mild pulmonary disease in a cystic fibrosis child homozygous for R553X. $₹$ Med Genet 1992;29:597.

9 Cutting G, Kalsch LM, Rosenstein BJ, et al. A cluster of cystic fibrosis mutations in the first nucleotide-binding fold of the cystic fibrosis conductance regulator protein. Nature 990;346:366-9.

10 Kalaydjieva L, Angelicheva D, Galeva I, et al. Cystic fibrosis in Bulgaria. $f$ Med Genet 1991;28:807.

11 Orita M, Suzuki Y, Sekiya T, Hayashi K. Rapid and sensitive detection of point mutations and DNA polymorphisms using the polymerase chain reaction. Genomics 1989;5:874-9.

12 Daar I, Maquat L. Premature translation termination mediates triosephosphate isomerase 8:802-13.

13 Bienvenu T, Beldjord C, Fonknechten N, et al. Severe cystic fibrosis in a child homozygous for the G542 nonsense mutation in the CFTR gene. $\mathcal{F}$ Med Genet 1993;30:621-4.

\section{Cutis laxa: a feature of Costello syndrome}

We were extremely interested to read the letter 'Cutis laxa and the Costello syndrome', ${ }^{1}$ in which the authors review case 5 of their previous paper describing children with cutis $\operatorname{laxa}^{2}$ and make a diagnosis of Costello syndrome. Recently, and independently, we have reviewed case 7 from the same paper and on both history and clinical examination made an unequivocal diagnosis of Costello syndrome. ${ }^{3}$

Now that two separate cases within this subgroup of congenital cutis laxa with retardation of growth and development have been independently diagnosed as Costello syndrome, it is obviously time for a review of this heterogeneous group and recognition of this syndrome as a differential diagnosis in congenital cutis laxa, especially in the presence of postnatal growth retardation and delayed development.

$$
\begin{array}{r}
\text { SARAH J DAVIES } \\
\text { HELEN E HUGHES } \\
\text { Institute of Medical Genetics, } \\
\text { University of Wales College of Medicine, } \\
\text { Heath Park, } \\
\text { Cardiff CF4 } 4 X W, \text { UK. }
\end{array}
$$

1 Patton MA, Baraitser M. Cutis laxa and the Costello syndrome. F Med Genet 1993;30:622.

2 Patton MA, Tolmie J, Ruthnum P, Bamforth S, Baraitser $\mathbf{M}$, Pembrey $\mathbf{M}$. Congenital cutis laxa with retardation of growth and development. f Med Genet 1987;24:556-61.

3 Martin RA, Lyons Jones K. Delineation of the Costello syndrome. Am $\mathcal{F}$ Med Genet 1991; 41:346-9.

\section{Fibrodysplasia ossificans progressiva}

I read with interest the article by Connor et al. 'A three generation family with fibrodysplasia ossificans progressiva' ( $\mathcal{F}$ Med Genet 1993;30:687-9). In the article, hip synovial osteochondromatosis was described and was said never to have been reported previously in FOP. In fact, Kalifa et al described this finding in Pediatric Radiology (1993;23:91-3) in an article entitled 'Fibrodysplasia ossificans progressiva and synovial chondromatosis in 10 and 15 year old patients'. Given these reports perhaps synovial chondromatosis deserves to be considered a feature of FOP.

THOMAS E HERMAN Department of Radiology, Washington University Medical Center, St Louis Children's Hospital, St Louis, Missouri 63110-1077, USA.

\section{Low segregation ratios in autosomal recessive disorders}

I read with interest the article by Bundey and Young ${ }^{1}$ on possible causes for low segregation ratios in autosomal recessive (AR) disorders. They hypothesise on possible mechanisms and explanations concerning the low segregation ratio in cartilage-hair hypoplasia $(\mathrm{CHH})$ found in Finland. ${ }^{2}$ I would like to add some further thoughts and possibilities to the behavioural, methodological, and biological factors that were described in their paper. ${ }^{1}$

1) Parents may decide to refrain from having further children, "even in the absence of genetic counselling"." This implies that with improvement of clinical genetic facilities, proper early genetic diagnosis, and adequate, non-directive counselling, segregation ratios in AR disorders will in future be even lower. As a result of this, we may then actually be measuring an effect of counselling upon parents' behaviour instead of bona fide biological mechanisms. It will then be difficult to find unbiased, that is, uncounselled, populations.

(2) Pregnancies which have been terminated after prenatal diagnosis will also have to be taken into account for the purpose of accurate ascertainment.

(3) Reduced penetrance in $\mathrm{CHH}$ has been found in both of the published population studies. ${ }^{23}$ In contrast to Mäkitie, ${ }^{2}$ Sulisalo et $a l^{4}$ found no evidence of reduced penetrance in Finnish $\mathrm{CHH}$ families. However, their conclusion was based on 14 small families selected for linkage analysis, where the proportion of affected sibs (after exclusion of the probands) was $0 \cdot 38$. The chance of finding even more (non-penetrant) affected sibs is unlikely, given the already high segregation ratio in this sample, and so the question of reduced penetrance is still open.

(4) McKusick et al, ${ }^{3}$ in their original paper, put forward environmental factors as a hypothetical cause of reduced penetrance and a low segregation ratio in $\mathrm{CHH}$ : either the homozygous phenotype is corrected by some normal dietary constituent or the homozygous phenotype becomes evident only in combination with some environmental factor. Although they refer to two $\mathrm{X}$ linked disorders to illustrate this possibility (G6PD deficiency and vitamin D resistant rickets ${ }^{3}$ ), environmental factors could also hypothetically lower the segregation ratio in AR disorders.

(5) Apparent reduced penetrance may partly be the result of ascertainment bias, since in most of the studies undertaken, short stature and $x$ ray abnormalities were the main criteria for diagnosis. ${ }^{2-6}$ But, in addition, variable expression, although uncommon in most AR disorders, may also cause a low segregation ratio. The occurrence of mild immunodeficiency without dwarfism has been described in $\mathrm{CHH}^{7}$ However, in most studies only short statured $\mathrm{CHH}$ patients have been checked for immunodeficiency, ${ }^{2-6}$ with the exception of one in which sibs were used as controls. ${ }^{8}$ Therefore $\mathrm{CHH}$ patients with only mild immunodeficiency could have been missed, thereby skewing the number of affected sibs.

The well known increased risk of intrauterine lethality in several AR disorders, though not in $\mathrm{CHH},{ }^{1}$ can be considered to be the most severe end of this spectrum of variability. Also the intrafamilial heterogeneity of cystic fibrosis, perhaps because of other modifying loci, ${ }^{9}$ makes it plausible that 